CATEGORY: Antibiotics and chemotherapeutics

\title{
7-BROMOINDIRUBIN-3'-OXIME UNCOVERS A SERINE PROTEASE-MEDIATED PARADIGM OF NECROTIC CELL DEATH
}

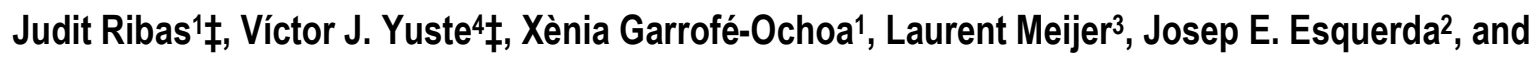
Jacint Boix ${ }^{1}$

${ }^{1}$ Molecular Pharmacology Group, Departament de Medicina Experimental, Universitat de Lleida, IRBLLEIDA, 25008 Lleida, Catalunya, Spain.

${ }^{2}$ Cell Neurobiology Unit, Departament de Medicina Experimental, Universitat de Lleida, IRBLLEIDA, 25008 Lleida, Catalunya, Spain.

${ }^{3}$ Cell Cycle Group \& UPS2682, CNRS, Station Biologique, 29682 Roscoff cedex, Bretagne, France.

${ }^{4}$ Cell Death, Senescence and Survival Research Group, Institut de Neurociències, Universitat Autònoma de Barcelona, 08193 Bellaterra, Catalunya, Spain.

KEYWORDS: Indirubin - Cell death - Mitochondria - Proteases - AIF

\section{¥ Should be considered first co-authors}

Corresponding author: Jacint Boix MD PhD, DME, Facultat de Medicina, Universitat de Lleida,

C/ Montserrat Roig 2, 25008 Lleida, Spain.

Tel: +34-973-702404 FAX: +34-973-702426 E-mail: jacint.boix@mex.udl.cat 


\section{ABSTRACT}

The new 7-bromoindirubin-3'-oxime (7BIO) compound induces caspase-independent cell death in all cell lines tested to date. Irrespective of the cell line, a $25 \mu \mathrm{M}$ treatment for 24 hours is lethal for the entire cell population. In SH-SY5Y and Jurkat cells, 7BIO $(25 \mu \mathrm{M})$ was found to collapse the mitochondrial transmembrane potential $(\Delta \Psi \mathrm{m})$ at only 2-3 hours of treatment. Concomitantly mitochondria swelled, cristae disrupted and, after 9 hours, external cell membranes ruptured. In addition, endoplasmic reticulum dilated and, unexpectedly, the acute cytoplasmic destruction yielded isolated nuclei with preserved morphology and DNA integrity. Furthermore, the process was independent of both Bax and Bak, since cell viability and $\Delta \Psi_{\mathrm{m}}$ decayed indistinguishably in double Bax-/-Bak-/- mouse embryonic fibroblasts (MEFs) and their wild type counterparts. Pharmacological inhibition of the mitochondrial permeability transition pore (MPTP) did not prevent $7 \mathrm{BIO}$-induced $\Delta \Psi_{\mathrm{m}}$ loss in none of the aforementioned cell lines. Caspase-independent inducers of cell death like AIF (Apoptosis Inducing Factor), cathepsins and calpains were not involved. Only the chemical inhibitors of serine proteases and, particularly, AEBSF afforded a significant protection thus suggesting a process regulated by this type of enzymes. As far as we know, these features are quite unique once taken together. Therefore we propose 7BIO is triggering a specific type of necrotic cell death. Finally, the cytotoxicity of 7BIO on apoptosis-resistant cells like double Bax-/-Bak-/- MEFs seems of great interest envisaging cancer therapy. 


\section{Introduction}

Cell necrobiology has been proposed to be the scientific discipline devoted to the study of the biological processes which predispose, precede or accompany cell death, as well as the consequences of cell demise for the tissue environment [1]. The impressive development of apoptosis research in the last 15 years has masked the lack of knowledge about the processes involved in other types of cell death. Electron microscopy studies of embryonic models provided the first hint about the existence of other types of programmed cell death [2]. In 2005, a Nomenclature Committee on Cell Death was created and established an official classification [3]. This classification was based on morphological features and was further complemented by other criteria, like the catabolic enzymes activated in each type of cell death [4].

Apoptosis (Type 1 cell death) and the pathways leading to it remain the most studied subject in cell necrobiology. Apoptosis is a complex phenotype of cell death. It results from caspase degradation of specific substrates. However, the lack of caspase activation does not necessarily preclude cell death or apoptosis. For instance, MCF-7, a human cell line derived from a breast cancer displaying a null expression of effector caspase 3, undergoes apoptosis facing typical apoptotic stimuli but with a non-apoptotic, atypical phenotype [5]. Autophagy (Type 2 cell death) has only recently entered and broadened the field of cell death. However, in addition to its killing role, autophagy is also a mechanism of survival for cells facing conditions such as starvation or hormone deprivation [6]. The resulting ambiguity is not an issue easy to solve and has prompted the proposal to define autophagic cell death as any death process with autophagic features but not necessarily autophagy being the cause of cell death [3]. Finally, necrosis (Type 3 cell death) and mitotic catastrophe ended the official classification [3, 4]. Necrosis has become a synonym of acute or accidental type of cell death. In other words, a scenario of cell homeostasis overwhelmed by one stressing stimulus or a combination of them. However, necrosis has also been observed to occur in a less acute and molecularly regulated way [7-10] Therefore, necrosis is presently an ill-defined term. 
Upon the discovery of the anti-leukemia properties of the indirubins contained in a traditional Chinese recipe, Danggui Longhui Wan [11], the synthesis and study of these compounds has become an active research area. Several protein kinases have been identified as targets of indirubins: CDKs [12], GSK3 [13] and others [14]. The bis-indole chemistry of indirubins provides a kinase inhibitor scaffold susceptible to chemical modification. As a consequence, new indirubin derivatives can be generated in order to obtain more selective or biologically interesting compounds. Several bromo-substituted indirubin-3'-oxime derivatives were synthesized and their inhibition profile on 85 protein kinases determined [14]. In this study, 7BIO proved to be fast and effective at inducing cell death in SH-SY5Y, a human neuroblastoma-derived cell line. In addition, the cell death process did not display any of the typical features of apoptosis. For example, the internuclesosomal DNA degradation, the nuclear pattern of chromatin condensation or the release of cytochrome c from mitochondria, were not observed. Consistently, no activation of effector caspases was detected and neither $\mathrm{Bcl}-2$ nor $\mathrm{Bcl}-\mathrm{XL}$ overexpression afforded any protection to cells treated with 7BIO. The caspase-independent process of cell death was also detected in other human cell lines, like neuroblastic IMR-5 and IMR-32, hematological HL-60 and Jurkat, etc.

In the present report, our purpose has been to progress in the characterization of the cell death process triggered by $7 \mathrm{BIO}$. We have demonstrated $7 \mathrm{BIO}$ induces a necrotic type of cell death characterized by early mitochondrial swelling and further cytoplasm disintegration. The involvement of proteins like calpains, cathepsins, Bax, Bak and AIF (Apoptosis Inducing Factor) has been discarded. Moreover, pharmacological inhibitors of the mitochondrial permeability transition pore (MPTP) have failed to prevent 7BIO-induced cell death and the early loss of mitochondrial transmembrane potential $\left(\Delta \Psi_{\mathrm{m}}\right)$. Finally, a pharmacological screening has suggested serine proteases could be regulating the death process. 


\section{Materials and Methods}

\subsection{Chemical reagents}

CellTiter $96 \circledR$ kit containing the MTS reagent and Cytotox $96 \circledR$ kit for LDH determinations were provided by Promega Biotech Ibérica, SL (Barcelona, Spain). 5BIO (5- bromoindirubin-3'-oxime) and 7BIO (7bromoindirubin-3'-oxime) compounds were synthesized in Prof. Skaltsounis' laboratory, University of Athens. zVADfmk (z-Val-Ala-Asp-fluoromethylketone), Q-VD-OPh (Q-Val-Asp(non-omethylated)-OPh) and AcDEVDafc (Acetyl-Asp-Glu-Val-Asp-7-amino-4-trifluoromethylcoumarin) were purchased from MP Biomedicals Europe (Asse-Relegem, Belgium). 3,3'-dihexyloxacarbocyanine iodide (DiOC6(3)) was supplied by Molecular Probes (Europe BV, Leiden, The Netherlands). Leupeptin was purchased from Roche (Barcelona, Spain). Cyclosporin A (CsA) and Calpeptin were purchased from Tocris bioscience (Bristol, UK). Staurosporine (STS), Bisbenzimide (Hoechst 33342), Bongkrekic acid (BKKA), DCl (3,4Dichloroisocoumarin), SuLLVYamc (N-Succinyl-Leu-Leu-Val-Tyr-7-amido-4-methylcoumarin), Pefabloc® SC (AEBSF or 4-(2-amino-ethyl)-benzene-sulfonyl-fluoride), Pepstatin A, PI (Propidium iodide), TPCK (N-pTosyl-L-phenylalanine-chloromethylketone), TLCK (N-a-Tosyl-L-lysine-chloromethylketone hydrochloride), zFAfmk (z-Phe-Ala-fluoromethylketone) and zFRamc (z-Phe-Arg-7-amido-4-methylcoumarin hydrochloride) were supplied by Sigma (Saint Louis, MO, USA). Unless otherwise stated, the non-listed reagents were also from Sigma.

\subsection{Cell culture and chemical treatments}

$\mathrm{SH}-\mathrm{SY} 5 \mathrm{Y}$ is a cell line derived from the metastasis of a human neuroblastoma. Jurkat, clone E6-1, is a human cell line derived from an acute T cell leukemia. Both cell lines were obtained from ATCC (Manassas, VA, USA). The immortalized mouse embryonic fibroblasts (MEFs) derived from double Bax-/-Bak-/- null mice and their wild type (w.t.) counterparts were gently provided by Dr. S.J. Korsmeyer laboratory [15, 16]. MEFs and SH-SY5Y cell lines were grown in 2 mM L-glutamine supplemented DMEM media plus antibiotics 
and a 10\% volume of FCS (Invitrogen, Barcelona, Spain). Jurkat cells were grown in RPMI 1640 media plus $10 \%$ FCS and antibiotics (Invitrogen, Barcelona, Spain). General culturing conditions were $37^{\circ} \mathrm{C}$ and a water-saturated, 5\% CO2 atmosphere. Plates with 6 (M6), 24 (M24) and 96 (M96) wells were used in our pharmacological and biochemical determinations. Plates, dishes and other plastic disposable tools for cell cultures were supplied by Iwaki (Chiba, Japan), Sarstedt (Newton, NC, USA), Bibby Sterilin (Staffordshire, UK) and Becton Dickinson (Franklin Lakes, NJ, USA). 7BIO and 5BIO were dissolved in DMSO at a concentration $10 \mathrm{mM}$. In order to improve $7 \mathrm{BIO}$ and 5BIO solubility, stock solutions were heated for 15 minutes at $60^{\circ} \mathrm{C}$ in a sonication bath, previous to their final addition to the culture media. Stock solutions of STS, Q-VD-OPh or the other compounds were also prepared with DMSO. From these stock solutions, the compounds were delivered to the culture media and adjusted to the final concentrations reported in the text and figures. The serial dilution procedure was used in concentration-dependency determinations. DMSO concentrations never surpassed $1 \%$ in the medium. At this concentration, we have observed no alteration in cell viability or differentiation status [17].

\subsection{Flow cytometry}

Flow cytometry analysis was performed on an EPICS ${ }$ XL instrument from Coulter Científica, SA (Madrid, Spain), equipped with an Argon ion laser (15 mW, $488 \mathrm{~nm}$ ) and a standard optical path and filter configuration for an analytical cytometer. The green fluorescence (FL1) of DiOC6(3) was collected through a 525/20 band pass filter. The red fluorescence (FL3) of PI, for example, was collected through a 620/15 band pass filter. Typical flow rates were between 150 and 300 cells per second, and a minimum of 10000 cells were analyzed per sample. Data acquisition was performed using System II (version 3.0) software (Coulter Cientifica, SA, Madrid, Spain). As a trigger signal, forward scatter was used with a threshold at a channel 10. Data was stored in list mode files and the subsequent analysis performed by means of the System II and the free software developed by Joseph Trotter (WinMDI 2.8). 


\subsection{Quantification of cell death}

Four alternative procedures were performed in order to quantify the ratios of cell death in the culture plates. The first one was based on the Trypan Blue dye, which enters and stains those cells with a disrupted external membrane. SH-SY5Y cells were preferentially subjected to this procedure along this report. On the other hand, in non-adherent Jurkat cells, staining with PI $(25 \mu \mathrm{g} / \mathrm{ml})$ and flow cytometry was chosen to detect and quantify the cells with breaches at the cell membrane. In MEFs and some pharmacological screenings we relied on the MTS reduction and the LDH release procedures, which we have described in detail before [17].

\subsection{Apoptosis assessment and quantification}

We have used several independent methods to assess and quantify apoptosis in the cell cultures. First, nuclear morphology as evidenced by direct $0.05 \mu \mathrm{g} / \mathrm{ml}$ bisBenzimide (Hoechst 33342) staining and fluorescence microscopy. Frequently, a double staining with bisBenzimide/PI was performed. In this case, $\mathrm{PI}$ concentration was $25 \mu \mathrm{g} / \mathrm{ml}$ like above. Second, the generation of large DNA fragments of approximately $50 \mathrm{kbp}$. This event was evidenced by means of agarose gels run in a contour homogeneous electric field (CHEF) system (BioRad, Hercules, CA, USA). The running conditions were 15 hours, at $6 \mathrm{~V} / \mathrm{cm}$, initial switching time of 50 seconds and final switching time of 90 seconds. Third, the detection of the ladder pattern of DNA degradation was done by a standard electrophoresis in $1.5 \%$ agarose gels. Fourth, the activity of DEVD targeted caspases. The procedure employed was based on reading the fluorescence released from an AcDEVDafc substrate after its direct addition to the culture medium, detergent cell lysis and incubation at $37^{\circ} \mathrm{C}$. All these procedures have been validated and described in our previous works [14, $17,18]$ 


\subsection{Electron microscopy}

Cells from treated or untreated cultures were collected, washed twice in PBS (150 mM CINa, $2.7 \mathrm{mM} \mathrm{CIK}, 8$ $\mathrm{mM} \mathrm{Na2HPO4,} 1.5 \mathrm{mM} \mathrm{KH} 2 \mathrm{PO} 4)$ and fixed for 30 minutes at $4^{\circ} \mathrm{C}$ in $100 \mathrm{mM}$ phosphate buffer (pH 7.4) containing $2.5 \%$ glutaraldehyde. After rinsing the pellets twice with PBS at $4^{\circ} \mathrm{C}$, cells were postfixed in buffered OsO4, dehydrated in graded acetone and embedded in Durcupan® ACM resin (Fluka, Buchs, Switzerland). Ultrathin sections mounted on copper grids were counterstained with uranyl acetate and lead citrate. A transmission electron microscope (Zeiss EM 910) was employed to visualize the cellular ultrastructure.

\subsection{Quantification of mitochondrial $\Delta \Psi \mathrm{m}$}

SH-SY5Y and Jurkat cells were plated onto M24 plates at a density of $1.5 \times 105$ cells/well and MEFs were plated onto M6 plates at a density of $2.5 \times 105$ cells/well. Following the treatments reported in the text and figures, DiOC6(3) reagent was added to the cultures to reach a final concentration of $40 \mathrm{nM}$. After 30minutes incubation, cells were harvested and analyzed by flow cytometry, as referred above. In most experiments, following an incubation in the DiOC6(3) reagent for 30minutes, PI was added for 15 additional minutes. The combined FL1 plus FL3 lectures yielded biparametric plots that allowed the simultaneous assessment of $\Delta \Psi \mathrm{m}$ and cell death.

\subsection{Protein extraction and Western Blotting}

To study the release of AIF from mitochondria, a $0.05 \%$ digitonin cytosolic extraction (Cyt.) was performed as we have reported before [17]. The remaining pellet was the mitochondrial containing fraction (Mit.) and contained other cells constituents like nuclei. This fraction was subjected to lysis in a buffer containing 100 mM Tris/CIH pH6.8, 2\%SDS, 1 mM EDTA, 1 mM PMSF, $2 \mu \mathrm{g} / \mathrm{ml}$ Aprotinin, $1 \mu \mathrm{g} / \mathrm{ml}$ Leupeptin and $1 \mu \mathrm{g} / \mathrm{ml}$ 
Pepstatin, by sonication and 5 minutes boiling. Following a centrifugation at $12000 \mathrm{~g}$ for 15 minutes the extract was obtained. Protein concentration was determined in the extracts by means of the DC Protein Assay from BioRad. Volumes were calculated to equalize the protein load in SDS 15\% polyacrylamide electrophoresis. Following transfer to Nitrocellulose $0.45 \mu \mathrm{m}$ filters (Schleicher and Schuell, Dassel, Germany), membranes were reacted with a dilution 1:40000 of the antiAlF polyclonal antibody (A7549) from Sigma. Immunoblots were finally developed with the antirabbit peroxidase conjugate antibody (A0545) from Sigma and the SuperSignal ${ }^{\circledR}$ West Pico reagent from Pierce (Rockford, IL, USA). Electrophoresis and electrotransfer equipments were the MINIPROTEAN III assemblies from BioRad.

\subsection{Calpain and cathepsin activity determinations}

Control, untreated, or treated cells were harvested and extracted with a buffer containing $20 \mathrm{mM} \mathrm{Tris} / \mathrm{ClH}$ pH 7.5, $150 \mathrm{mM} \mathrm{NaCl}, 1 \%$ Triton-X-100, $1 \mathrm{mM}$ DTT and $1 \mathrm{mM}$ AEBSF for 10 minutes on ice. After a centrifugation at $12000 \mathrm{~g}$ for 15 minutes, protein was quantified in the supernatants as previously described (DC Protein Assay, BioRad). Equal amounts of protein $(20 \mu \mathrm{g})$ were delivered to the wells of a M96 plate. Volumes were equalized with distilled water to $50 \mu$ l. If calpain activity was determined, one volume of a buffer containing $100 \mathrm{mM}$ Tris/CIH pH 7.5, 16 mM DTT, 20 mM CaCl and $200 \mu \mathrm{M}$ SuLLVYamc was added. If cathepsin activity was determined, one volume of a buffer containing $40 \mathrm{mM}$ Sodium Acetate, $8 \mathrm{mM}$ EDTA, 8 mM DTT, 2 mM AEBSF and $200 \mu$ M zFRamc (pH6) was added. Then, M96 plates were incubated for $5 \mathrm{~h}$ at $37^{\circ} \mathrm{C}$ in the dark and fluorescence (excitation $360 / 40$, emission $460 / 40$ ) was quantified by means of a FL600 plate reader from Biotek Instruments, Inc. (Winooski, VT, USA). 


\section{Results}

\subsection{Non-apoptotic, necrotic-like features were found in the cell death process triggered by 7BIO}

In our previous characterization of several indirubin derivatives, we have demonstrated that two related compounds 5-bromoindirubin-3'-oxime (5BIO) and 7BIO behaved quite differently at inducing cell death. While the former was a caspase-dependent, apoptosis inducer, the latter triggered a caspase-independent type of death. Both compounds caused cell-death in a concentration-dependent manner. Irrespective of the cell line, after 24 hours of treatment, $\mathrm{LC}_{50}$ and $\mathrm{LC}_{100}$ neared $12.5 \mu \mathrm{M}$ and $25 \mu \mathrm{M}$ for $7 \mathrm{BIO}$, respectively. On the other hand, 5BIO $(25 \mu \mathrm{M})$ caused death in approximately the $60 \%$ of SH-SY5Y cells treated for 24 hours [14]. In the present work we have focused more on the time course of the cell death caused by these compounds. For instance, we characterized the kinetics of caspase activation. As shown, $5 \mathrm{BIO}(25 \mu \mathrm{M})$ displayed a clear time-dependent activation of DEVD-targeting caspases, while $7 \mathrm{BIO}(25 \mu \mathrm{M})$ yielded values repeatedly beneath those of control cells (Fig. 1A). Consistently, Q-VD-Oph (10 $\mu \mathrm{M})$, a chemical inhibitor of caspases characterized by its broad spectrum and selectivity for caspase inhibition was not modifying the aspect of nuclei in the cells challenged with 7BIO (Fig. 1B). Following a double staining with bisBenzimide/PI, fluorescence microscopy showed 7BIO caused the nuclei to have a slightly condensed look irrespective of Q-VD-Oph presence. Nuclei became also globular because cells were detached from the cultures plates. The caspase-inhibiting activity of Q-VD-Oph was certified by the blockage of the apoptotic phenotype observed in 5BIO-treated SH-SY5Y cells (Fig. 1B). Finally, the bisBenzimide/PI staining allowed the counting of apoptotic nuclei. As shown, the percentage increased in a time dependentmanner in 5BIO-treated SH-SY5Y cells. On the opposite, the ratios never surpassed those of untreated, time 0 , in 7BIO-treated cells (Fig. 1C). In conclusion, for further experiments $5 \mathrm{BIO}$ was used to induce apoptosis as the closest relative of 7BIO. However, cell death by $7 \mathrm{BIO}$ became the subject of our research.

Electron microscopy was the first approach to gain insight into the type of cell death triggered by 7BIO. For this purpose, SH-SY5Y cells were fixed and studied at different times following a treatment with 
$25 \mu \mathrm{M}$ 7BIO. Control untreated cells displayed a rounded morphology with a large nucleus containing a diffuse euchromatin and, often, two ostensible nucleoli (Fig. 2A). In the cytoplasm, endoplasmic reticulum was poorly developed and an enlarged Golgi apparatus was frequently seen. Mitochondria displayed discernible cristae (Fig. 2C). Following a 3 hours treatment, the most prominent trait was endoplasmic reticulum dilation. Interestingly, nuclear envelop was generally spared from dilating (Fig. 2B). Mitochondria were also damaged displaying a swelled look and disrupted cristae. Small, medium and large size dilations of the reticulum could be observed and regarded as progressive phases of injury. Similarly, different stages of mitochondrial cristae disruption could be seen in a cell (Fig. 2D). By 9 hours of treatment, we were surprised to realize cytoplasm had disintegrated and most cells converted into isolated nuclei (Fig. 2E). In spite of the complete cytoplasm destruction, nuclear integrity was remarkable. At 9 hours or later times, a minor proportion of cells could be still observed retaining the cytoplasm. Interestingly, in these cells, autophagic multi-lamellar structures were persistently found (Fig. 2F).

Jurkat cells were chosen, as a second cell line to investigate 7BIO mode of action, mainly because of their non-adherent growth in culture and the subsequent simplicity to perform flow cytometry determinations. The death kinetics of Jurkat cells challenged with 7BIO was found to reproduce that of $\mathrm{SH}$ SY5Y (Fig. 3A). Dead cells began to appear between 3 and 6 hours of treatment. After 12 hours, almost all the cell membranes had lost their impermeability. The process in Jurkat cells was also independent of caspases, as evidenced by the null effect of Q-VD-Oph on cell death ratios (Fig. 3B). Upon a 7BIO treatment and electron microscopy, Jurkat cells displayed a morphological pattern of cell death identical to the one just reported in SH-SY5Y cells. Four additional cell lines (HL-60, MCF-7, IMR-5 and IMR-32) were also characterized and reproduced this death pattern when treated with 7BIO (not shown).

\subsection{BIO-induced cell death and the decrease of $\Delta \Psi \mathrm{m}$ is not mediated by either Bax or Bak proteins}


The previous morphological studies suggested 7BIO was causing an early effect on mitochondria. This fact and the central role of mitochondria in many cell death processes, prompted us to explore the involvement of this organelle in 7BIO deadly effects. The dilation of mitochondria has been correlated with the loss of mitochondrial membrane potential $(\Delta \Psi \mathrm{m})$, therefore we characterized this parameter by means of the DiOC6(3) fluorochrome and flow cytometry. DiOC6(3) is a membrane-permeable reagent that accumulates in healthy mitochondria displaying physiological values of $\Delta \Psi_{\mathrm{m}}$. The reduction $\Delta \Psi_{\mathrm{m}}$ implies a decrease of the cell fluorescence. A decreased fluorescence was found after a treatment with $7 \mathrm{BIO}(25 \mu \mathrm{M})$ for 9 hours, either in SH-SY5Y or in Jurkat cells (Fig. 4A).

In the apoptotic models of cell death, mitochondrial damage is mediated by the proapoptotic members of the Bcl-2 family of proteins, essentially Bax and Bak. We wondered what the lethality of 7BIO would be if tested on cells not expressing Bax and Bak proteins. Therefore, we proceeded to compare the effects of 7BIO on mouse embryonic fibroblasts (MEFs), either w.t. or double Bax-/- Bak-/-. The MTS reduction procedure was employed to determine the percentage of cell viability (not shown). The LDH release procedure was used to quantify the percentages of cell death (Fig. 4B). Both approaches yielded consistent and complementary results. Precisely, 7BIO was inducing the death of both types of MEFs in the same range of concentrations and in a concentration-dependent manner. Consequently, the absence of Bax and Bak proteins did not confer any cell resistance to the 7BIO compound. On the other hand, as expected from cells defective in Bax and Bak, Stauroporine (STS) was not able to trigger apoptosis in these cells. Next, we explored the effects of double Bax/Bak deficiency on $\Delta \Psi_{\mathrm{m}}$ dissipation by $7 \mathrm{BIO}$ (Fig. $4 \mathrm{C}$ ). The result was that $\Delta \Psi \mathrm{m}$ collapsed only after 3 hours of treatment and double Bax/Bak deficiency was neither minimizing nor significantly delaying the collapse. Finally, we were concerned about the null expression of Bax and Bak modifying the death phenotype caused by 7BIO. Consequently, we decided to perform electron microscopy studies on w.t. and double Bax-/-Bak-/- MEFs under 7BIO treatment (Fig. 5). The progressive dilation of the endoplasmic reticulum leading to cytoplasm disintegration and cell death 
was detected in both types of MEFs. In conclusion, Bax and Bak proteins were not required for $7 \mathrm{BIO}$ to kill the cells.

\subsection{BIO-induced loss of $\Delta \Psi \mathrm{m}$ was not counteracted by inhibitors of the MPTP}

Once Bax and Bak protein were discarded as elements mediating $7 \mathrm{BIO}$ effects on cell viability and $\Delta \Psi \mathrm{m}$, we focused on the role played by the mitochondrial permeability transition pore (MPTP). The adenosine nucleotide translocator (ANT) is the inner mitochondrial component of the channel regulating $\Delta \Psi \mathrm{m}$. Bongkrekic acid (BKKA) is a chemical agent able to block ANT opening and to counteract $\Delta \Psi_{\mathrm{m}}$ loss [19]. Similarly, by acting on ANT-associated cyclophilin D, Cyclosporin A (CsA) is able to neutralize ANTmediated $\Delta \Psi \mathrm{m}$ loss [20]. The protective effect of both compounds was assayed on SH-SY5Y and Jurkat cells challenged with $7 \mathrm{BIO}$. We found no rescue effect either on cell death or on $\Delta \Psi_{\mathrm{m}}$ dissipation by the presence of either $50 \mu \mathrm{M}$ BKKA or $2 \mu \mathrm{M}$ CsA in the culture medium (Fig. 6). Next, we thought of the possibility that $7 \mathrm{BIO}$ could have a double mode of action consisting of Bax and/or Bak activation plus MPTP opening. This would mean one mechanism of $\Delta \Psi_{\mathrm{m}}$ loss being able to compensate for the blockage of the other. This caveat led us to test the effects of BKKA and CsA on double Bax-/-Bak-/- MEFs (Fig. 7). Moreover, we tested BKKA plus CsA added together on Bax-/-Bak-/- MEFs facing 7BIO (not shown). In all experimental conditions, neither cell death nor $\Delta \Psi_{\mathrm{m}}$ loss was meaningfully reduced. In conclusion, MPTPinhibiting agents were not able to antagonize $7 \mathrm{BIO}$-induced $\Delta \Psi_{\mathrm{m}}$ collapse and the null role of Bax and Bak proteins was further reinforced.

\subsection{Neither AIF translocation nor DNA degradation were detected in cells treated with 7BIO}

AIF (Apoptosis Inducing Factor) is a flavoprotein that is located in the mitochondria and which functional activity is characterized by being double and opposed [21]. If placed at the mitochondrial inner membrane, AIF displays cytoprotective actions. Upon mitochondrial outer membrane permeabilization, its translocation 
seems to be responsible for many of the caspase-independent traits of apoptosis. Consequently, we considered mandatory to explore the putative involvement of AIF in the lethal effects of 7BIO. We proceeded to determine if AIF became present in the cytosol upon a treatment with 7BIO. SH-SY5Y (Fig. $8 \mathrm{~A}$ ) and Jurkat (not shown) cells were fractioned as reported in the materials and methods section and the AIF content in the cytosolic and mitochondrial fractions was determined by Western Blot. As shown, AIF remained in the mitochondrial fraction along the dying process triggered by 7BIO. As a positive control of AIF translocation, we used the apoptosis-inducing $5 \mathrm{BIO}$ compound. As expected, $5 \mathrm{BIO}$ caused AIF release from mitochondria in the cells undergoing apoptosis. In addition, we explored the degradation of cell chromatin (Fig. 8B). 5BIO treatment caused the apoptotic laddering of DNA while 7BIO was not producing this low molecular weight type of chromatin degradation, in agreement with a previous report [14]. Next we studied the high molecular weight fragmentation of chromatin, which was clearly observed in cells treated with $5 \mathrm{BIO}$ but absent from 7BIO-treated ones. In conclusion, these fragmentation patterns are distinctive traits of apoptosis but are not found in 7BIO-induced cell death. Moreover, the overall integrity of DNA is consistent with the preserved morphology of nuclei and chromatin observed in the previous ultrastructural studies.

\subsection{BIO was not triggering calpain- or cathepsin-type protease activity}

Calpain and cathepsin, like caspases, are cysteine proteases which activation has been implicated in the necrotic type of cell death $[7,8]$. Therefore, we proceeded to analyze their involvement in the death process triggered by 7BIO. First we tested the effect of several pharmacological inhibitors of these enzymes on SHSY5Y and Jurkat cells. Calpeptin is known to be an inhibitor of calpain and cathepsin L proteases. zFAfmk is an inhibitor of cathepsins $B$ and $L$. Leupeptin inhibits cathepsins $A$ and $B$ among other cysteine plus serine proteases included in its spectrum. Finally, zVADfmk is a general inhibitor of caspases with the ability to inhibit other cysteine proteases, for instance calpains and cathepsins, at a concentration of $100 \mu \mathrm{M}$ [22]. 
The specific capase inhibitor Q-VD-Oph, that is unable to inhibit calpains and cathepsins, was used as a control. In a summary, the presence of these inhibitors did not change the ratios of cell lethality caused by 7BIO (Fig. 9A). In addition, calpain activity was assessed directly by means of a fluorescence-releasing substrate (Fig. 9B). The increase of calpain activity detected in SH-SY5Y cells challenged with 7BIO was negligible. Cathepsin activation was also checked by an analogous approach in Jurkat cells treated with 7BIO (Fig. 9C). While 5BIO treatment activated cathepsins significantly, 7BIO displayed activation values undistinguishable from untreated cells. In conclusion, neither calpains nor cathepsins seemed engaged in the $7 \mathrm{BIO}$ mode of action.

\subsection{The activity of serine proteases was involved in 7BIO-induced cell death}

In order to find a molecular event actively involved in the 7BIO mechanism of cell killing, we decided to perform a broad pharmacological screening. We searched for a compound or family of compounds with the ability to revert the death process, either stopping or significantly delaying it. Based on the results described before, 9 hours was considered the optimal time point for the detection of a putative protective effect. The SH-SY5Y cells and the MTS procedure were chosen to perform the screening. Substances able to prevent cell oxidative stress or calcium overload, like N-Acetylcysteine, Nifedipine, BAPTA AM and Ruthenium Red were combined with 7BIO, but did not modify the cell death process. Proteasome inhibitors like Lactacystin and Bortezomib were also tested and did not reverse 7BIO lethality. Finally, 3-methyladenine and necrostatin-1, as pharmacological inhibitors of autophagy [23] and necroptosis [24] respectively, failed to antagonize 7BIO toxicity (not shown). Among all the chemicals tested, some serine protease inhibitors were those with the most remarkable ability to block the cell death process in both, SH-SY5Y and Jurkat cell lines (Fig. 10A). These compounds are chemically unrelated and share the property of inhibiting serine proteases. Therefore, the involvement of a serine protease activity, which is inhibited by TPCK, DCI and, particularly, the AEBSF compound but not TLCK, was concluded. 
AEBSF continued to protect the cells from 7BIO after 24 hours of treatment, although to a lesser extent than at 9 hours (not shown). When times longer than 24 hours were analyzed, AEBSF intrinsic lethality impaired any solid conclusion (not shown). To better characterize the AEBSF protective effect, we determined $\Delta \Psi_{\mathrm{m}}$ in Jurkat cells challenged with $7 \mathrm{BIO}$ and $7 \mathrm{BIO}$ plus AEBSF (Fig. 10B). These

experiments revealed $\Delta \Psi_{\mathrm{m}}$ loss as soon as 2 hours after $7 \mathrm{BIO}$ treatment, thus indicating again a very initial mitochondrial injury. Furthermore, AEBSF was clearly demonstrating a protective effect on mitochondria. In conclusion, we propose the involvement of the proteolytic activity of at least one, yet undetermined, serine protease in the 7BIO mode of action.

\section{Discussion}

The new indirubin derivative 7BIO has demonstrated to be a fast and efficient cell killer in all the cell lines we have tested so far. The death process is characterized by being caspase-independent and, accordingly, not to show apoptotic features like typical nuclear condensation plus fragmentation, DNA laddering or cytochrome $\mathrm{c}$ translocation to the cytoplasm. In addition, we have proved the process not to be mediated by p53 and to be insensitive to either $\mathrm{Bcl}-2$ or Bcl-XL proteins [14]. In this report we have attempted to gain insight into the cell death process caused by 7BIO. Electron microscopy provided evidence of an identical morphological pattern, irrespective of the cell type studied. The pattern consisted of early mitochondrial swelling and cristae disruption, progressive dilation of the endoplasmic reticulum and final destruction of the cytoplasm yielding isolated nuclei with a remarkable preserved structure. Though a diffuse increase in chromatin condensation could be observed, it was different from the peripheral, AIF-mediated stage-1 type [25]. In agreement, a kinetic analysis of AIF protein translocation ruled out AIF participation. Moreover, the release of AIF from mitochondria is known to require either calpain or cathepsin activation $[22,26]$. Consistently, neither calpain nor cathepsin protease activity was triggered in cells by the 7BIO action. 
The observation of injured mitochondria early in the death process prompted us to focus on $\Delta \Psi \mathrm{m}$ disruption, as a representative parameter of the mitochondrial function. In Jurkat cells we found $\Delta \Psi_{\mathrm{m}}$ decreased as soon as 2 hours following 7BIO treatment. This was in accordance with the timing observed for the morphological disruption of mitochondria. The collapse of $\Delta \Psi_{\mathrm{m}}$ can be caused by either Bax/Bak protein activation or the MPTP opening [27]. Therefore, double Bax-/-Bak-/- MEFs were studied and a null involvement of both proteins was found. CsA and BKKA are two chemical agents with the ability to block the opening of the ANT component of the MPTP $[19,20]$. Neither was able to prevent cell death or $\Delta \Psi_{\mathrm{m}}$ disruption in the four cell lines tested, SH-SY5Y, Jurkat, w.t. and double Bax-/-Bak-/- MEFs. The fact that CsA and BKKA acting on Bax-/- Bak-/- MEFs made no difference, allowed to discard 7BIO might simultaneously act on two different targets Bax/Bak proteins and the MPTP. However, in relation to MPTP involvement, nothing could be definitively concluded. Even though the reversion of $\Delta \Psi_{\mathrm{m}}$ disruption by $\mathrm{CsA}$ and BKKA suggests the involvement of the MPTP, a negative result cannot be interpreted as proving its non-involvement. MPTP could be activated by a yet undiscovered mechanism triggered by $7 \mathrm{BIO}$ and insensitive to the effects of CsA and BKKA. For example, a hypothetical mechanism not mediated by ANT, the target of both CsA and BKKA. In addition, the possibility of an MPTP-independent mechanism could be envisaged as the cause of $\Delta \Psi_{\mathrm{m}}$ disruption.

What is the molecular target for 7BIO? The bis-indole structure of 7BIO suggests an ATP competing action and, therefore, protein kinases are the first target candidates. However, up to date, 85 protein kinases have been studied and discarded as responsible for this type of cell death [14]. Alternatively, we are thinking of exploring the elements constituting the mitochondrial respiratory chain as possible targets. The disruption of mitochondrial respiration is a good hypothesis for an MPTP-independent mechanism to disrupt $\Delta \Psi_{\mathrm{m}}$. On the other hand, in 7BIO triggered cell death, we have identified the involvement of a protease activity which is characterized by its sensitivity to serine protease inhibitors and, particularly, to AEBSF. AEBSF is a chemical inhibitor of serine proteases and several apoptotic features are known to be 
neutralized by this compound $[28,29]$. Long ago, we described the ability of TLCK, a trypsin-like protease inhibitor, to inhibit cycloheximide-induced cell death in N18, a mouse neuroblastoma cell line [30]. Interestingly, N18 cells underwent an unusual vacuolated type of apoptosis facing the inhibition of new protein synthesis with cycloheximide. Other authors have identified TLCK sensitive serine proteases in apoptosis and named them serpases [31]. However, none of these reports were dealing with a necrotic type of cell death like the one triggered by 7BIO. Moreover, our results show no involvement of a TLCK sensitive, trypsin-like, serine protease and, instead, point to a TPCK sensitive, chymotrypsin-like, one. Such an activity has been described in the proteasome and $\mathrm{DCl}$ compound is known to be a proteasome inhibitor at the concentration we have used. Since specific inhibitors of the proteasome did not modify 7BIO-induced lethality, we do not support a role for proteasome activation in the 7BIO mode of action.

There is a general agreement not to create a plethora of names to identify processes of cell death with specific features [3]. For instance, we were very cautious not to propose a name for an atypical cell death process that ended up being a defective type of apoptosis caused by the absence of CAD, the Caspase-Activated DNAse protein [32]. Concerning 7BIO-triggered death process, we propose to consider it a specific type of necrosis. Based on this report results and those previously published [14], we believe there is sufficient evidence to no longer suspect that 7BIO-type of cell death is a defective phenotype of apoptosis. Is it autophagic cell death? Indeed, autophagy has been observed in the cell corpses but its role in causing cell death is doubtful. First, autophagy seems not to be present in most cells. Second, in 7BIO challenged cells, we have assayed 3-methyladenine at concentrations able to block autophagy [23]. Neither a rescue nor a deleterious effect was found. Third, $\mathrm{Bcl}-2$ is known to prevent autophagic cell death by it ability to neutralize the protein Beclin [33]. We have reported the null effect of Bcl-2 overfunction on the 7BIO lethal effects [14]. These facts strongly support our doubts about autophagy being the 7BIO mode of cell killing. Autophagy has been defined as a cell death process not necessarily caused by autophagy but with autophagy being present [3]. Based on this definition, we could define as autophagic the cell death 
process triggered by 7BIO. However, we do not favor this option. First, as just mentioned, autopahgy seems not to affect the entire cell population. Second, we believe the nomenclature of a cell death type should be as informative as possible about the mechanisms leading to it. In conclusion, we prefer to maintain the term necrosis (Type III cell death) to define the 7BIO-induced death process.

Recently, a lot of interest has been raised by several paradigms of necrosis as molecularly regulated processes of cell death. In these paradigms, cyclophilin $\mathrm{D}$, calpains and cathepsins are expected to have a determinant role [7-10] However, in the present report, their involvement has been ruled out. Furthermore, the lack of cathepsin activation precludes the involvement of the lysosomes and a lysosomaltype cell death. The cell ultrastructure caused by $7 \mathrm{BIO}$ evoked a cell death process observed in embryonic development and named cytoplasmic type [2]. However, any relationship with the 7BIO induced death process is merely speculative. Unless the embryonic process can be transferred, for example, to cell culturing conditions to allow molecular analyses, it will be very difficult to find a potential correlate. This is why we have not used cytoplasm disintegration or cytoplasmic type as a very suitable nomenclature for the 7BIO-induced cell death. Several models of atypical cell death have been described so far. Paraptosis is characterized by caspase 9 activation and a late occurrence of mitochondria swelling [34], therefore it is clearly different from the 7BIO-trigered process. Necroptosis displays distinctive features of necrosis and autophagy very similar to the ones we have described here [24]. The death preventive effect of necrostatin1 is what allows the identification of necroptosis experimentally, but necrostatin- 1 has not protected cells from the $7 \mathrm{BIO}$ challenge. In conclusion, $7 \mathrm{BIO}$ triggers a necrotic process with a combination of original traits. We propose 7BIO reveals a specific paradigm of necrotic cell death.

$7 \mathrm{BIO}$ is a new chemical agent with a great toxicity on cells in culture conditions, either proliferating or in a quiescent differentiated state [14]. In this report, 7BIO displays the ability to kill cells totally resistant to apoptosis through the intrinsic pathway. Therefore, a therapeutic potential for apoptosis-resistant cancer can be suggested. However, many questions remain. What is the target of $7 \mathrm{BIO}$ and how is it causing cell 
death? Is 7BIO engaging a physiological mechanism of cell death or is it accidental? What the toxicity of 7BIO will be when assayed in an animal model? These caveats notwithstanding, 7BIO is already a challenging compound for necrobiologists, presently available for further research.

\section{Acknowledgements}

We thank Prof. Leandro Skaltsounis (University of Athens) for a continued collaboration and indirubinderivatives provision. We thank Claudio Hetz (Harvard School of Public Health) and Joan X. Comella (University of Lleida) for mediating in the process of obtaining the MEFs. This work was supported by project PI041488 and PI070498 granted to the Mol. Pharmacology Group by FIS, "Instituto de Salud Carlos III" (Spain). VJY is in the 2006 "Ramon y Cajal" Program from the "Ministerio de Educación y Ciencia" (Spain), co-financed by the European Social Fund. XGO is a predoctoral fellow from AGAUR. ("Generalitat de Catalunya"). While performing this work, JR was supported by a fellowship from IRBLLEIDA.

\section{References}

[1] Darzynkiewicz Z, Juan G, Li X, Gorczyca W, Murakami T, Traganos F. Cytometry in cell necrobiology: analysis of apoptosis and accidental cell death (necrosis). Cytometry 1997;27:1-20.

[2] Clarke PG. Developmental cell death: morphological diversity and multiple mechanisms. Anat Embryol (Berl) 1990;181:195-213. 
[3] Kroemer G, El-Deiry WS, Golstein P, Peter ME, Vaux D, Vandenabeele P, et al. Classification of cell death: recommendations of the Nomenclature Committee on Cell Death. Cell Death Differ 2005;12 Suppl 2:1463-7.

[4] Galluzzi L, Maiuri MC, Vitale I, Zischka H, Castedo M, Zitvogel L, et al. Cell death modalities: classification and pathophysiological implications. Cell Death Differ 2007;14:1237-43.

[5] Janicke RU, Ng P, Sprengart ML, Porter AG. Caspase-3 is required for alpha-fodrin cleavage but dispensable for cleavage of other death substrates in apoptosis. J Biol Chem 1998;273:15540-5.

[6] Tsujimoto Y, Shimizu S. Another way to die: autophagic programmed cell death. Cell Death Differ 2005;12 Suppl 2:1528-34.

[7] Zong WX, Thompson CB. Necrotic death as a cell fate. Genes Dev 2006;20:1-15.

[8] Golstein P, Kroemer G. Cell death by necrosis: towards a molecular definition. Trends Biochem Sci $2007 ; 32: 37-43$

[9] Moubarak RS, Yuste VJ, Artus C, Bouharrour A, Greer PA, Menissier-de Murcia J, et al. Sequential activation of poly(ADP-ribose) polymerase 1, calpains, and Bax is essential in apoptosis-inducing factormediated programmed necrosis. Mol Cell Biol 2007;27:4844-62.

[10] Bras M, Yuste VJ, Roue G, Barbier S, Sancho P, Virely C, et al. Drp1 mediates caspaseindependent type III cell death in normal and leukemic cells. Mol Cell Biol 2007;27:7073-88. 
[11] Xiao Z, Hao Y, Liu B, Qian L. Indirubin and meisoindigo in the treatment of chronic myelogenous leukemia in China. Leuk Lymphoma 2002;43:1763-8.

[12] Hoessel R, Leclerc S, Endicott JA, Nobel ME, Lawrie A, Tunnah P, et al. Indirubin, the active constituent of a Chinese antileukaemia medicine, inhibits cyclin-dependent kinases. Nat Cell Biol 1999;1:607.

[13] Leclerc S, Garnier M, Hoessel R, Marko D, Bibb JA, Snyder GL, et al. Indirubins inhibit glycogen synthase kinase-3 beta and CDK5/p25, two protein kinases involved in abnormal tau phosphorylation in Alzheimer's disease. A property common to most cyclin-dependent kinase inhibitors? J Biol Chem 2001;276:251-60.

[14] Ribas J, Bettayeb K, Ferandin Y, Knockaert M, Garrofe-Ochoa X, Totzke F, et al. 7-Bromoindirubin3'-oxime induces caspase-independent cell death. Oncogene 2006;25:6304-18.

[15] Lindsten T, Ross AJ, King A, Zong WX, Rathmell JC, Shiels HA, et al. The combined functions of proapoptotic Bcl-2 family members bak and bax are essential for normal development of multiple tissues. Mol Cell 2000;6:1389-99.

[16] Wei MC, Zong WX, Cheng EH, Lindsten T, Panoutsakopoulou V, Ross AJ, et al. Proapoptotic BAX and BAK: a requisite gateway to mitochondrial dysfunction and death. Science 2001;292:727-30. 
[17] Ribas J, Boix J. Cell differentiation, caspase inhibition, and macromolecular synthesis blockage, but not BCL-2 or BCL-XL proteins, protect SH-SY5Y cells from apoptosis triggered by two CDK inhibitory drugs. Exp Cell Res 2004;295:9-24.

[18] Ribas J, Gomez-Arbones X, Boix J. Caspase 8/10 are not mediating apoptosis in neuroblastoma cells treated with CDK inhibitory drugs. Eur J Pharmacol 2005;524:49-52.

[19] Furlong IJ, Lopez Mediavilla C, Ascaso R, Lopez Rivas A, Collins MK. Induction of apoptosis by valinomycin: mitochondrial permeability transition causes intracellular acidification. Cell Death Differ 1998;5:214-21.

[20] Kroemer G, Dallaporta B, Resche-Rigon M. The mitochondrial death/life regulator in apoptosis and necrosis. Annu Rev Physiol 1998;60:619-42.

[21] Modjtahedi N, Giordanetto F, Madeo F, Kroemer G. Apoptosis-inducing factor: vital and lethal. Trends Cell Biol 2006;16:264-72.

[22] Yuste VJ, Moubarak RS, Delettre C, Bras M, Sancho P, Robert N, et al. Cysteine protease inhibition prevents mitochondrial apoptosis-inducing factor (AIF) release. Cell Death Differ 2005;12:1445-8.

[23] Seglen PO, Gordon PB. 3-Methyladenine: specific inhibitor of autophagic/lysosomal protein degradation in isolated rat hepatocytes. Proc Natl Acad Sci U S A 1982;79:1889-92.

[24] Degterev A, Huang Z, Boyce M, Li Y, Jagtap P, Mizushima N, et al. Chemical inhibitor of nonapoptotic cell death with therapeutic potential for ischemic brain injury. Nat Chem Biol 2005;1:112-9. 
[25] Yuste VJ, Sanchez-Lopez I, Sole C, Moubarak RS, Bayascas JR, Dolcet X, et al. The contribution of apoptosis-inducing factor, caspase-activated DNase, and inhibitor of caspase-activated DNase to the nuclear phenotype and DNA degradation during apoptosis. J Biol Chem 2005;280:35670-83.

[26] Polster BM, Basanez G, Etxebarria A, Hardwick JM, Nicholls DG. Calpain I induces cleavage and release of apoptosis-inducing factor from isolated mitochondria. J Biol Chem 2005;280:6447-54.

[27] Kroemer G, Galluzzi L, Brenner C. Mitochondrial membrane permeabilization in cell death. Physiol Rev 2007;87:99-163.

[28] Egger L, Schneider J, Rheme C, Tapernoux M, Hacki J, Borner C. Serine proteases mediate apoptosis-like cell death and phagocytosis under caspase-inhibiting conditions. Cell Death Differ 2003;10:1188-203.

[29] de Bruin EC, Meersma D, de Wilde J, den Otter I, Schipper EM, Medema JP, et al. A serine protease is involved in the initiation of DNA damage-induced apoptosis. Cell Death Differ 2003;10:1204-12.

[30] Boix J, Fibla J, Yuste V, Piulats JM, Llecha N, Comella JX. Serum deprivation and protein synthesis inhibition induce two different apoptotic processes in N18 neuroblastoma cells. Exp Cell Res 1998;238:4229.

[31] Grabarek J, Du L, Johnson GL, Lee BW, Phelps DJ, Darzynkiewicz Z. Sequential activation of caspases and serine proteases (serpases) during apoptosis. Cell Cycle 2002;1:124-31. 
[32] Yuste VJ, Bayascas JR, Llecha N, Sanchez-Lopez I, Boix J, Comella JX. The absence of oligonucleosomal DNA fragmentation during apoptosis of IMR-5 neuroblastoma cells: disappearance of the caspase-activated DNase. J Biol Chem 2001;276:22323-31.

[33] Pattingre S, Tassa A, Qu X, Garuti R, Liang XH, Mizushima N, et al. Bcl-2 antiapoptotic proteins inhibit Beclin 1-dependent autophagy. Cell 2005;122:927-39.

[34] Sperandio S, de Belle I, Bredesen DE. An alternative, nonapoptotic form of programmed cell death. Proc Natl Acad Sci U S A 2000;97:14376-81.

\section{Figure Legends}

Fig. 1 - Characterization of the cell death process induced in SH-SY5Y cells by the 5BIO and 7BIO compounds. (A) SH-SY5Y cells were treated for the times indicated in the graph with $25 \mu \mathrm{M} 5 \mathrm{BIO}, 25 \mu \mathrm{M}$ $7 \mathrm{BIO}$ or $0.5 \%$ DMSO, which was used as the vehicle of the BIO compounds. Then, DEVD-targeted caspase activity was determined. Average \pm Standard Error of Media (SEM) of three determinations is shown. (B) SH-SY5Y cells were treated for 9h with $25 \mu \mathrm{M}$ 5BIO, $25 \mu \mathrm{M} 7 \mathrm{BIO}$ or left untreated. In identically treated cultures, $10 \mu \mathrm{M} Q-V D-O p h$ was added. A double direct staining with bisBenzimide and PI was performed and cells were subjected to fluorescence microscopy. Scale bar equals $20 \mu \mathrm{m}$. (C) SH-SY5Y cells were treated as indicated in the figure to determine the time-course of apoptosis induction. Following bisBenzimide staining, fluorescence microscopy allowed the counting of apoptotic nuclei. Only those displaying unmistakable traits of apoptosis were counted. Bar value is the mean \pm SEM of two independent experiments with a minimal of 200 cells counted per condition. 
Fig. 2 - Electron microscopy of the cell death process induced in SH-SY5Y cells by the 7BIO compound. (A) Control untreated SH-SY5Y cells. The Golgi apparatus, G, and mitochondria, m, are indicated. (B) SH-SY5Y cells treated for 3 hours with $25 \mu \mathrm{M} 7 \mathrm{BIO}$. In the centrally displayed cell, arrowheads point to dilations of the endoplasmic reticulum (medium size dilations). In a neighboring cell, an arrowhead is used to mark a greater size dilation of the reticulum. A cluster of mitochondria, $m$, further shown at greater magnification is indicated. (C) The Golgi apparatus, $G$, and mitochondria, $\mathrm{m}$, of the healthy cell, above, are shown at greater magnification. A detail of the nuclear envelope and chromatin, $\mathrm{N}$, is also shown. (D) At greater magnification, the mitochondrial cluster, $m$, indicated above. The cluster shows different stages of the disruption caused by 7BIO. As previously, the arrowhead points to the endoplasmic reticulum dilations. Here, the small size dilations are emphasized. (E) SH-SY5Y cells treated for 9 hours with $25 \mu \mathrm{M}$ 7BIO. Two preserved and isolated nuclei, N, surrounded by subcellular debris are seen. (F) SHSY5Y cells treated for 12 hours with $25 \mu \mathrm{M} 7 \mathrm{BIO}$. Arrows point to autophagosomes. The nucleus, $\mathrm{N}$, and mitochondria, m, can be identified. Many independent cells were characterized by electron microscopy at the time points reported before. The selected images are representative of traits observed reproducibly.

Fig. 3 - Characterization of the cell death process induced in Jurkat cells by the 7BIO compound. (A) SH-SY5Y and Jurkat cells were treated with $25 \mu \mathrm{M} 7 \mathrm{BIO}$ and cell death was quantified at the times shown in the x-axis. In SH-SY5Y, the Trypan Blue procedure was employed to assess cell death ratios. In nonadherent Jurkat cells, PI staining and flow cytometry was preferred. Irrespective of the method, three independent experiments and three independents counts were done. Bar value is the calculated mean \pm SEM. (B) SH-SY5Y and Jurkat cells were also treated for 9 hours with either $25 \mu \mathrm{M} 7 \mathrm{BIO}$ or $25 \mu \mathrm{M} 7 \mathrm{BIO}$ plus $10 \mu \mathrm{M}$ Q-VD-Oph to ascertain an eventual involvement of caspases in Jurkat cell death. The effects of Q-VD-Oph and the DMSO vehicle alone were also tested. Cell death was determined and calculated as before. 
Fig. 4 - Effects of $7 \mathrm{BIO}$ on $\Delta \Psi \mathrm{m}$. (A) SH-SY5Y and Jurkat cells were treated with $7 \mathrm{BIO}(25 \mu \mathrm{M})$ or the DMSO vehicle as stated in the figure. Then, $\Delta \Psi_{\mathrm{m}}$ was determined by means of the DiOC6(3) reagent. The displayed histograms are representative of several independent experiments. (B) Double Bax-/-Bak-/-and w.t. MEFs were treated for 24 hours with 7BIO and STS as reported in the x-axis. Cell death (\%) was measured by means of the LDH release procedure. LDH determination of STS treatment was performed at 48 hours. Average \pm SEM of at least two independent experiments with three independent measurements per experiment are shown. (C) Double Bax-/-Bak-/- and w.t. MEFs were treated with 7BIO $(25 \mu \mathrm{M})$ as indicated in the figure and $\Delta \Psi_{\mathrm{m}}$ was determined as before. Reproducible results were obtained in several independent experiments.

Fig. 5 - Examination by electron microscopy of MEFs treated with 7BIO. (A) Ultrastructure of control, untreated, w.t. MEFs. (B,C) The w.t. MEFs treated with 7BIO $(25 \mu \mathrm{M})$ for 9 hours. (D) Ultrastructure of double Bax-/-Bak-/-MEFs untreated. (E) Bax-/-Bak-/-MEFs challenged with 7BIO $(25 \mu \mathrm{M})$ for 3 hours. (F) Bax-/-Bak-/-MEFs treated with 7BIO $(25 \mu \mathrm{M})$ for 9 hours. Arrowheads are used to emphasize great size (in B) and medium size (in E) dilations of the endoplasmic reticulum. Isolated and well preserved nuclei, $\mathrm{N}$, characterize the later phases of the process. The images shown are representative of the morphologies observed.

\section{Fig. 6- Effects on $\Delta \Psi \mathrm{m}$ of SH-SY5Y and Jurkat cells treated with 7BIO plus inhibitors of MPTP}

opening. SH-SY5Y and Jurkat cells were treated for 9 hours as stated in the figure. The concentrations were $25 \mu \mathrm{M}$ for $7 \mathrm{BIO}, 50 \mu \mathrm{M}$ for BKKA and $2 \mu \mathrm{M}$ for CsA. Following a double staining with DiOC6(3) and PI as described in the methods section, cells were collected and subjected to flow cytometry. FL-1 (DiOC6(3)) registered events are plotted on the $y$-axis. FL-3 $(\mathrm{PI})$ registered events are plotted on the $\mathrm{x}$-axis. The 
reduction of $\Delta \Psi \mathrm{m}$ plus cell membrane rupture is detected as a migration from the upper left quadrant to the lower right one. The biparametric plots displayed are representative of at least two independent experiments.

Fig. 7- Effects on $\Delta \Psi \mathrm{m}$ of double Bax-/-Bak-/- and w.t. MEFs treated with $7 \mathrm{BIO}$ plus inhibitors of MPTP opening. Double Bax-/-Bak-/- and w.t. MEFs were treated for 9 hours as stated in the figure. The concentrations were $25 \mu \mathrm{M}$ for 7BIO, $50 \mu \mathrm{M}$ for BKKA and $2 \mu \mathrm{M}$ for CsA. Cells were stained and analyzed by flow cytometry as described in the previous figure. The biparametric plots displayed are representative of at least two independent experiments.

Fig. 8 - AIF translocation and DNA degradation analysis of SH-SY5Y cells treated with 7BIO. (A) SHSY5Y cells were treated with 7BIO $(25 \mu \mathrm{M})$ for the times indicated in the figure, $5 \mathrm{BIO}(25 \mu \mathrm{M})$ for 9 hours, or the DMSO vehicle. Cells were fractionated into a cytosolic (Cyt.) and a mitocondrial-containing fraction (Mit.), as reported in the materials and methods section. The content of AIF (62 kDa) in the fractions was detected by means of Western Blotting. AAIF ( $57 \mathrm{kDa}$ ) states for truncated AIF, the form of AIF released from mitochondria upon a protease cleavage. (B) SH-SY5Y cells were treated for 24 hours as stated in the figure. The concentration of $7 \mathrm{BIO}$ and $5 \mathrm{BIO}$ was $25 \mu \mathrm{M}$. DNA laddering was studied by means of electrophoresis in $1.5 \%$ agarose gels. High molecular DNA fragmentation was analyzed by means of agarose gels and CHEF electrophoresis.

Fig. 9 - Calpain- and cathepsin-type proteases are not involved in the 7BIO-trigered process of cell death. (A) SH-SY5Y and Jurkat cells were incubated with the protease inhibitors indicated in the figure for half an hour and, then, treated with 7BIO. Cell death was determined after 9 hours of coincubation by means of Trypan blue (SH-SY5Y) or PI staining (Jurkat). The percentages displayed are the mean \pm SEM 
of three independent counts and three independent experiments. (B) SH-SY5Y cells were treated for 9 hours with STS $(1 \mu \mathrm{M})$ or $7 \mathrm{BIO}(25 \mu \mathrm{M})$ and calpain activity was quantified by means of a fluorescent substrate. Bar value in arbitrary fluorescent units is the mean \pm SEM of five independent experiments. (C) Jurkat cells were treated for 9 hours with STS $(1 \mu \mathrm{M}), 5 \mathrm{BIO}(25 \mu \mathrm{M})$ and $7 \mathrm{BIO}(25 \mu \mathrm{M})$ and cathepsin activity was determined by means of a fluorescent substrate. Values in arbitrary fluorescent units are the average \pm SEM of five independent experiments.

Fig. 10 - Inhibitors of serine proteases protect cells from the challenge of 7BIO. (A) SH-SY5Y and Jurkat cells were treated for 9 hours with 7BIO, 7BIO plus Q-VD-Oph or several serine protease inhibitors as stated in the figure. The percentage of cell death was obtained by the Trypan blue (SH-SY5Y) and PI (Jurkat) procedures, as reported in the methods section. The percentages displayed are the mean \pm SEM of three independent counts and three independent experiments. (B) Jurkat cells were treated with $25 \mu \mathrm{M}$ 7BIO (white bars) or $25 \mu \mathrm{M} 7 \mathrm{BIO}$ plus $300 \mu \mathrm{M}$ AEBSF (grey bars) and the percentage of cells with a marked reduction in the fluorescence of DiOC6(3) was calculated at different time points. The average \pm SEM of three independent experiments is displayed. 
Fig. 1.
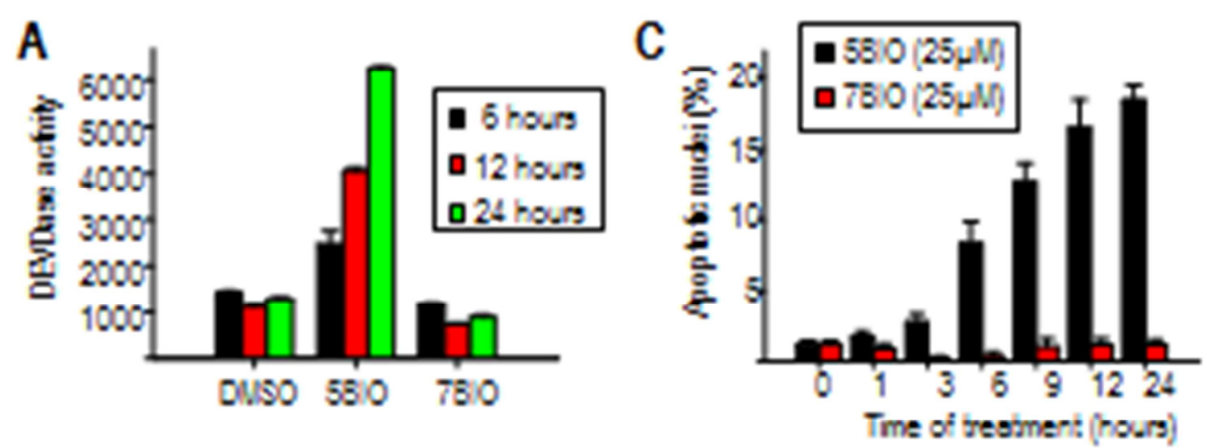

B

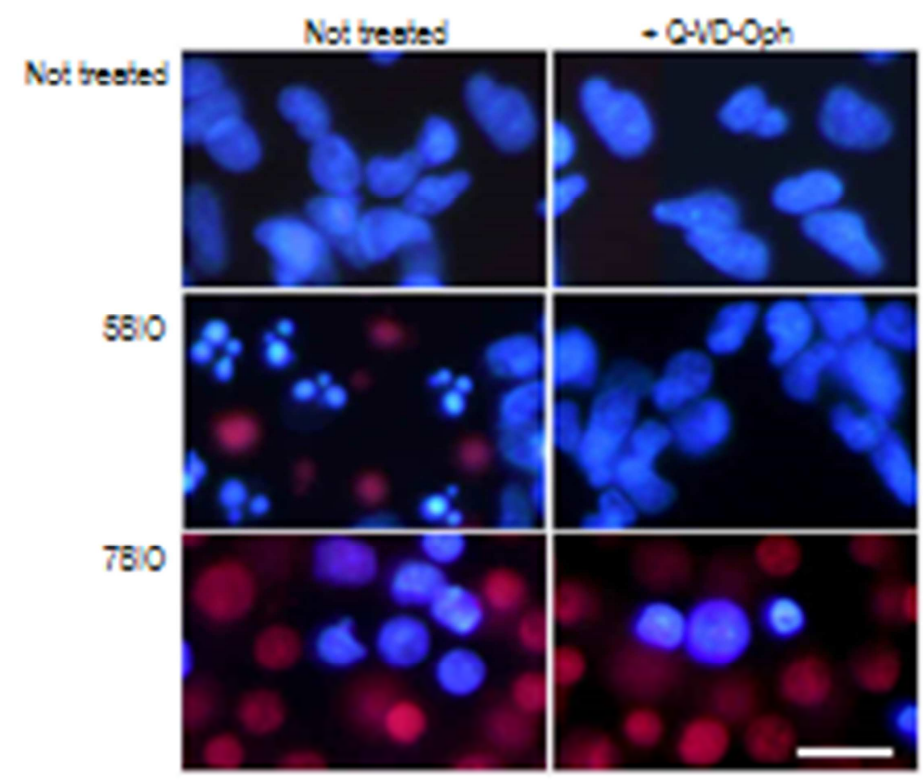


Fig. 2.
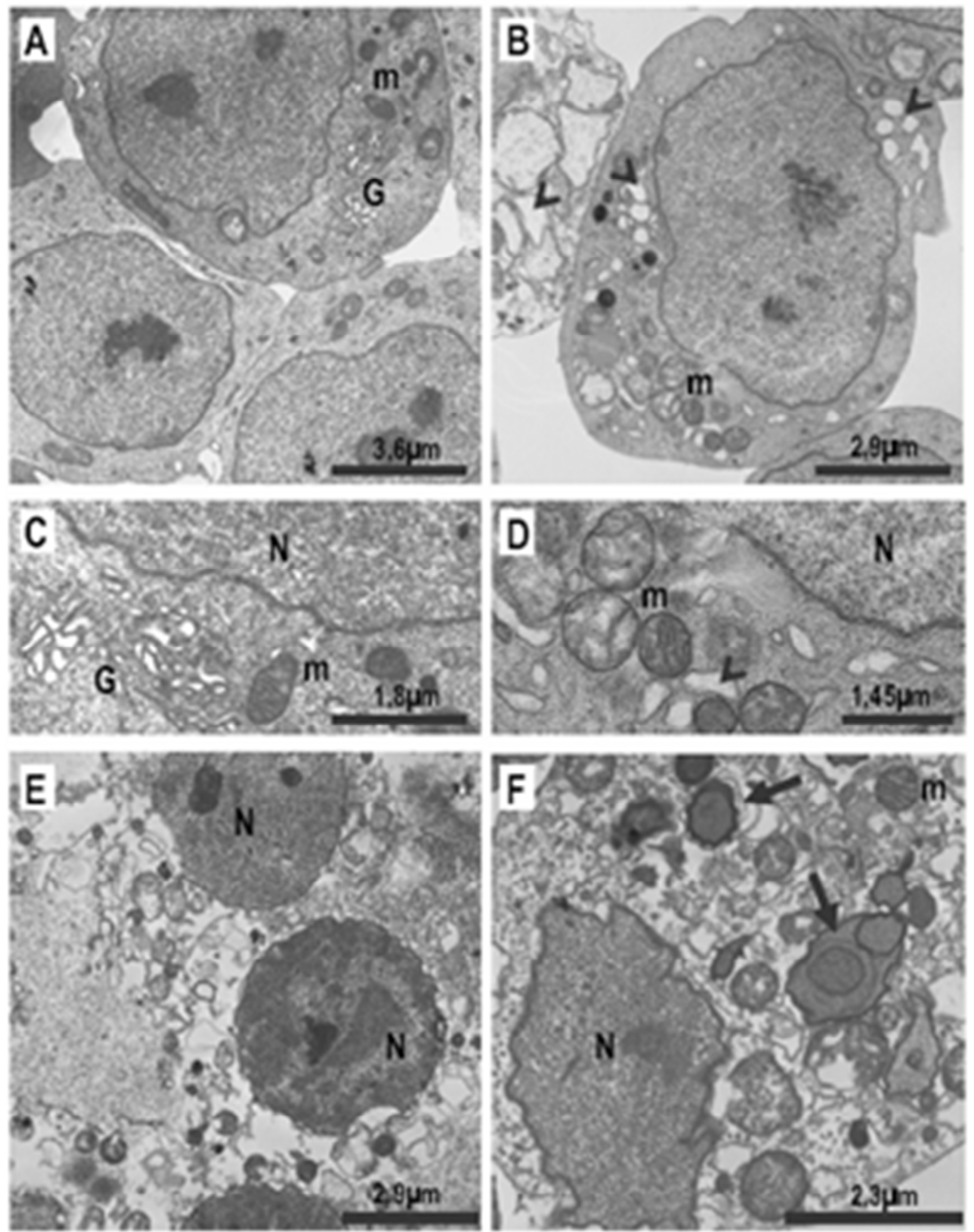
Fig. 3.

A

- SH-SY5Y $\square$ Jurkat

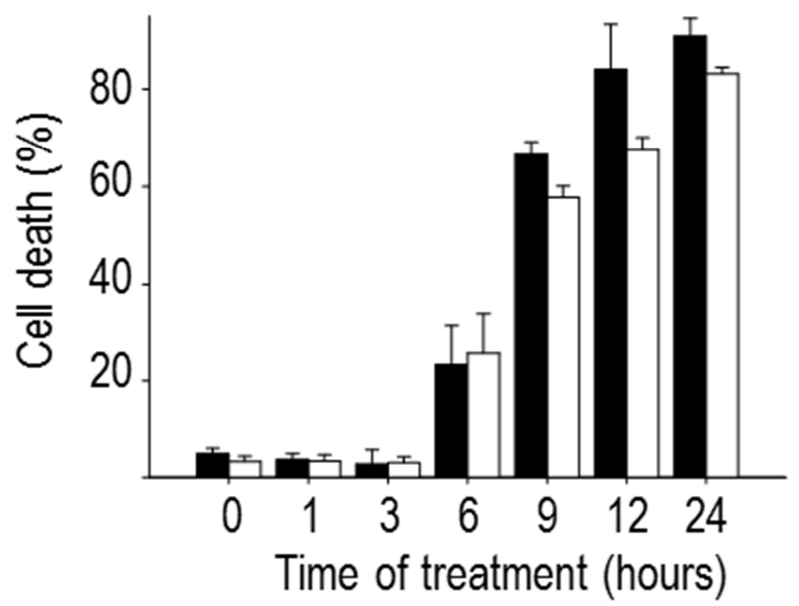

B

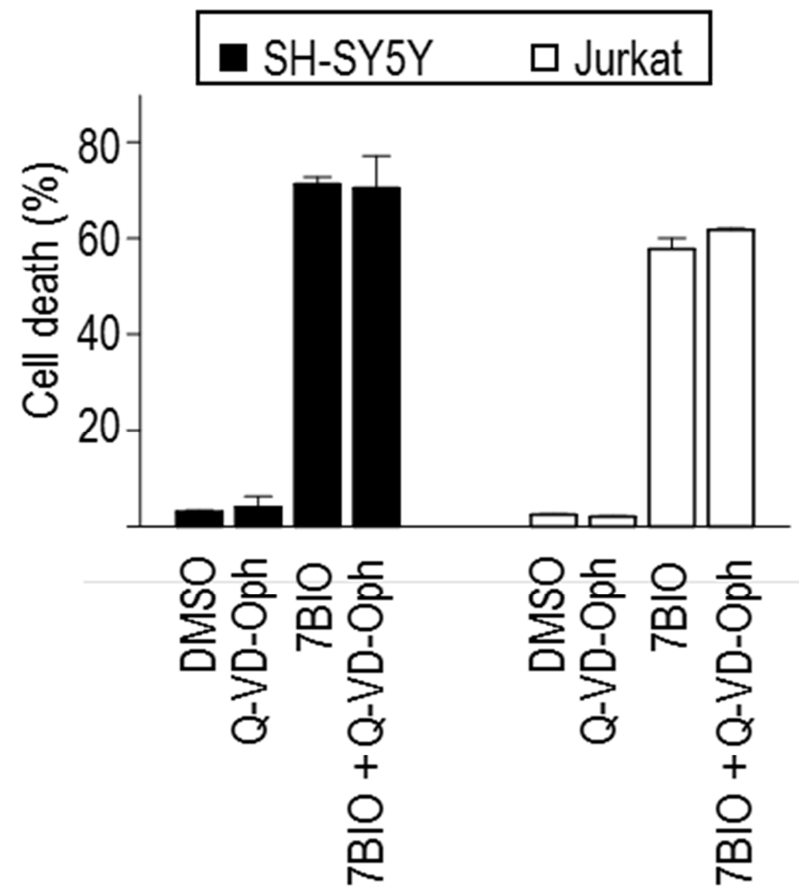


Fig. 4.

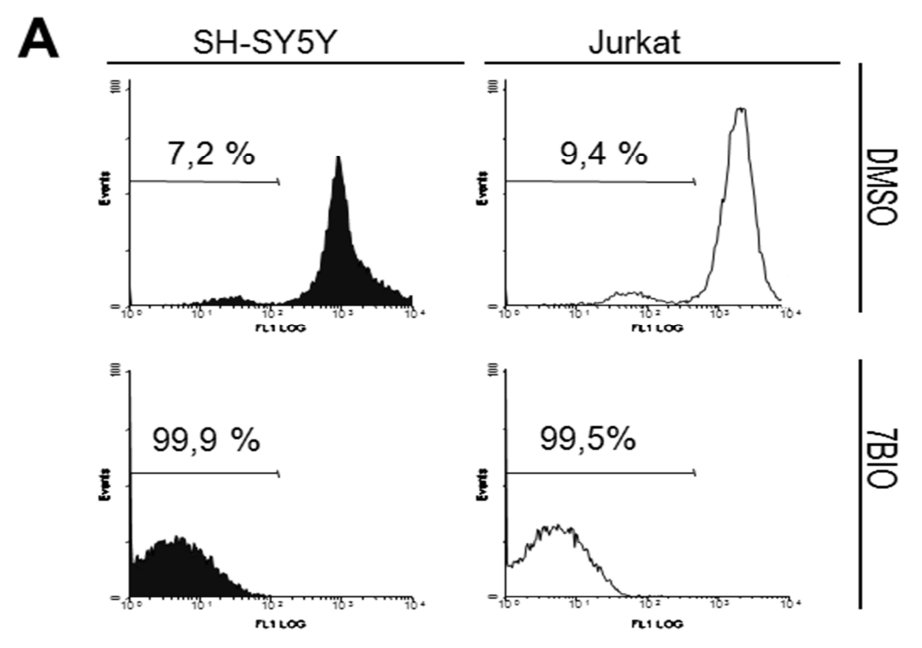

B

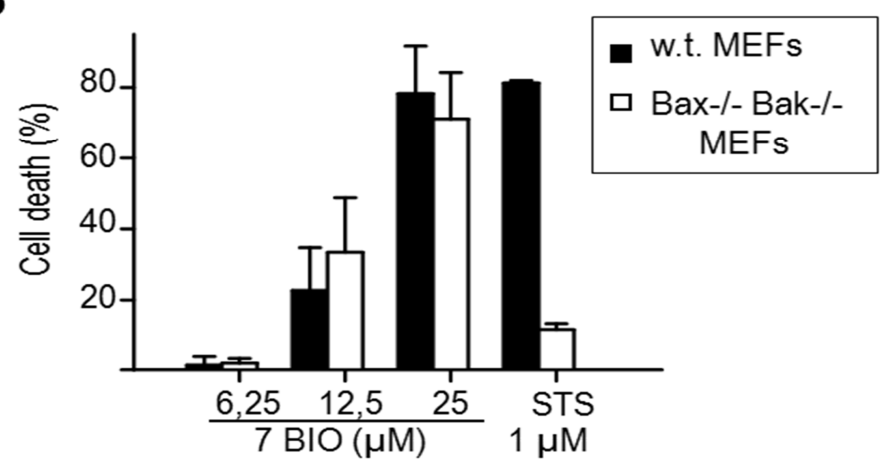

C

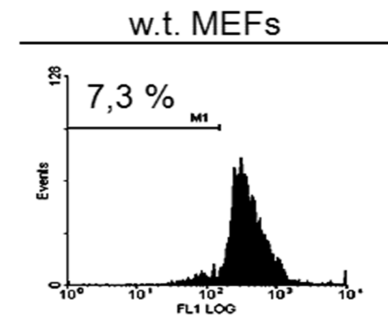

Bax-/- Bak-/- MEFs
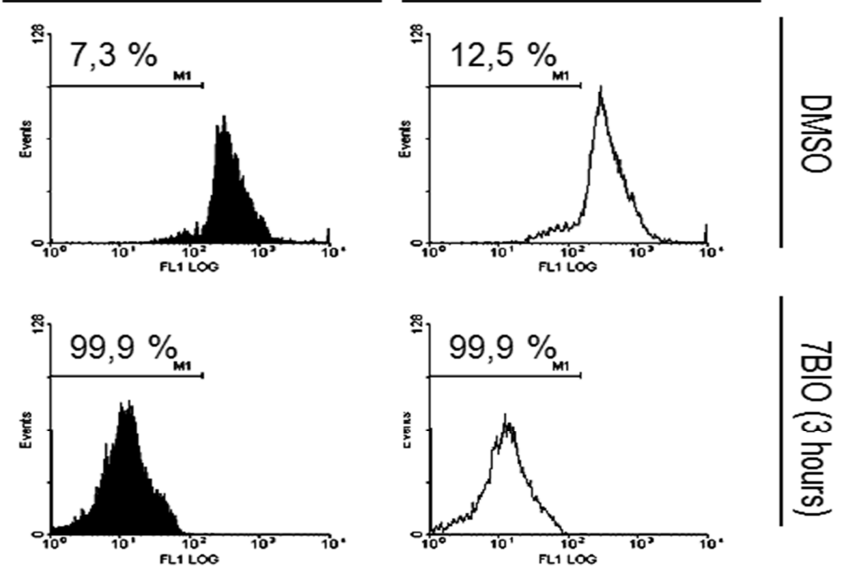

$\mid \frac{0}{0}$ 
Fig. 5.
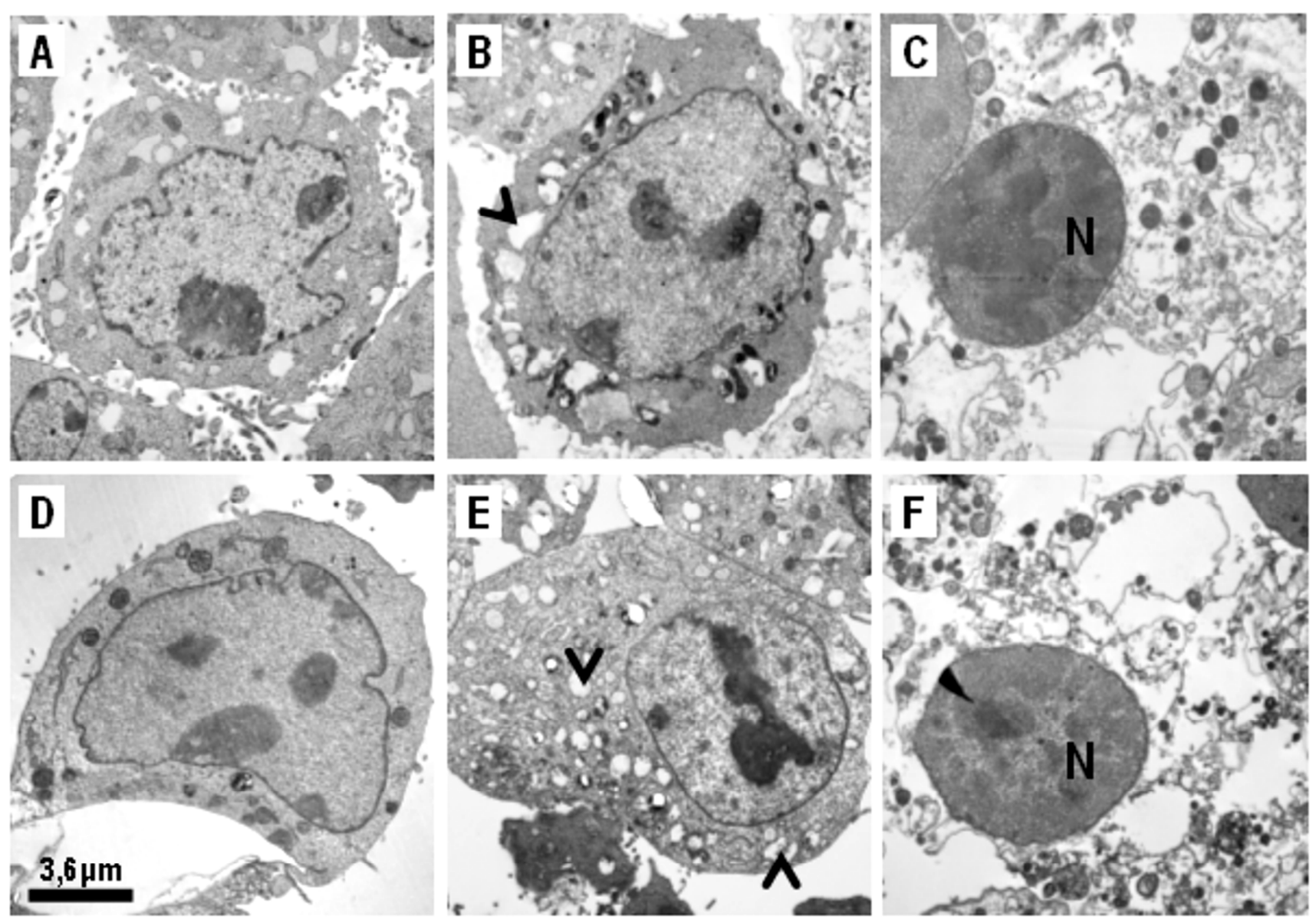
Fig. 6.

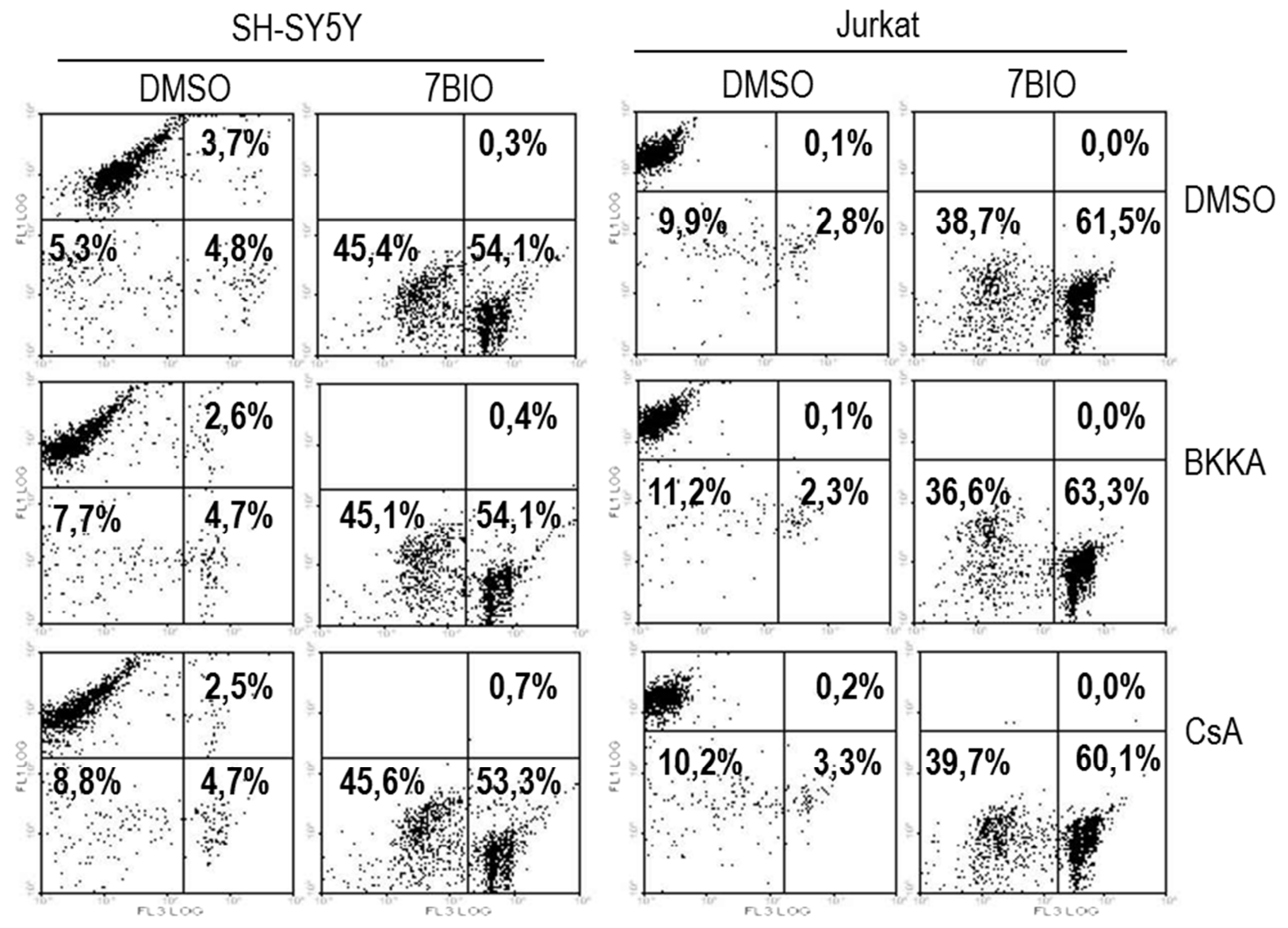


Fig. 7.

w.t. MEFs

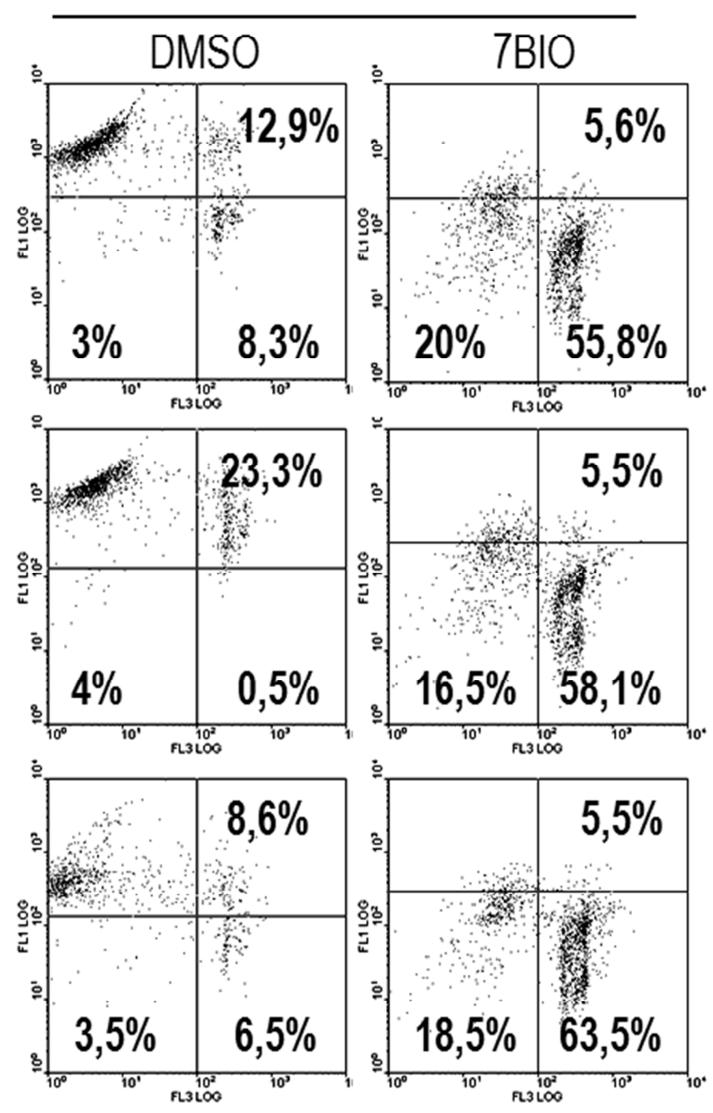

Bax-/- Bak-/- MEFs

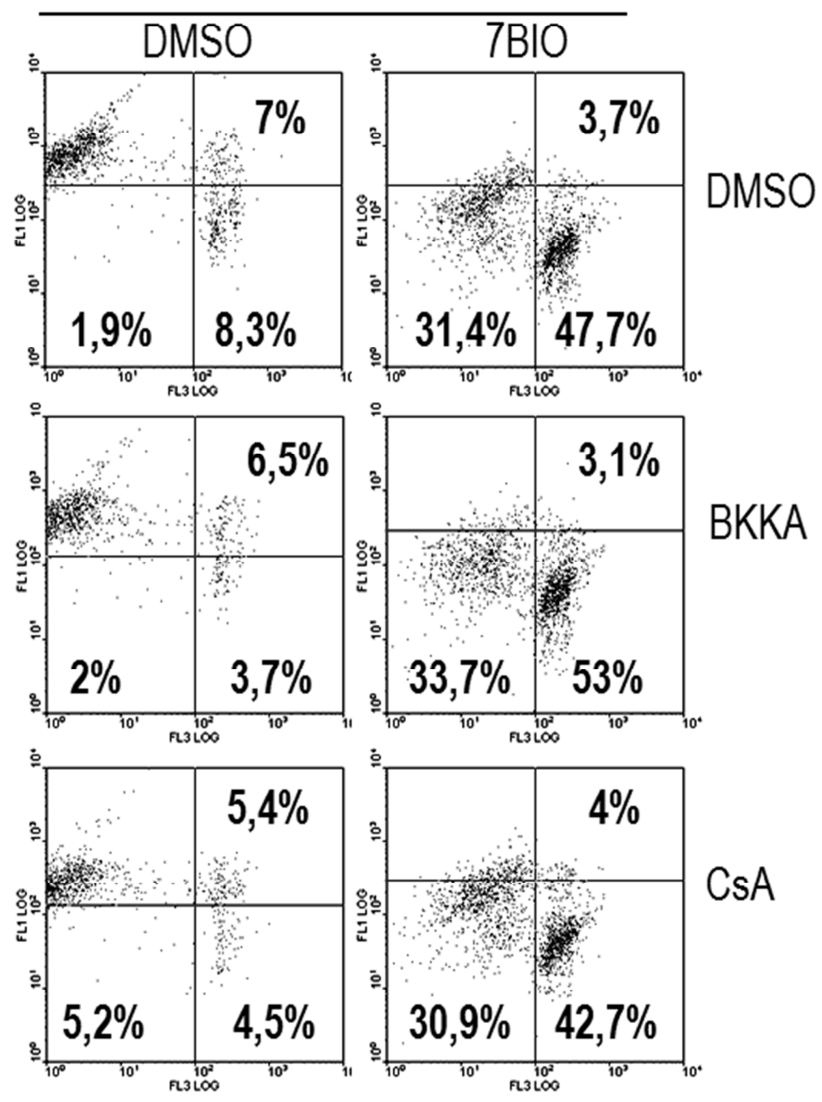


Fig. 8.

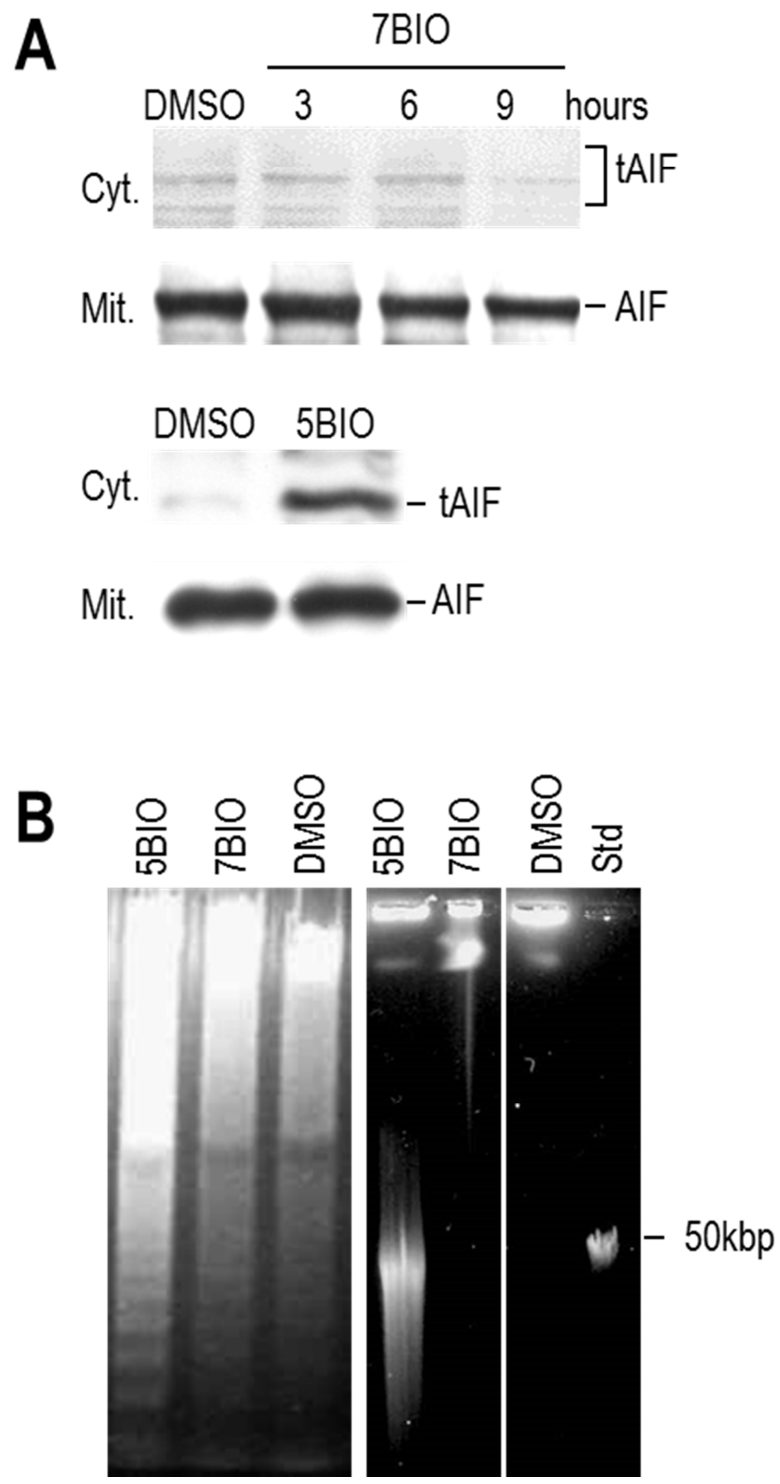


Fig. 9.

A

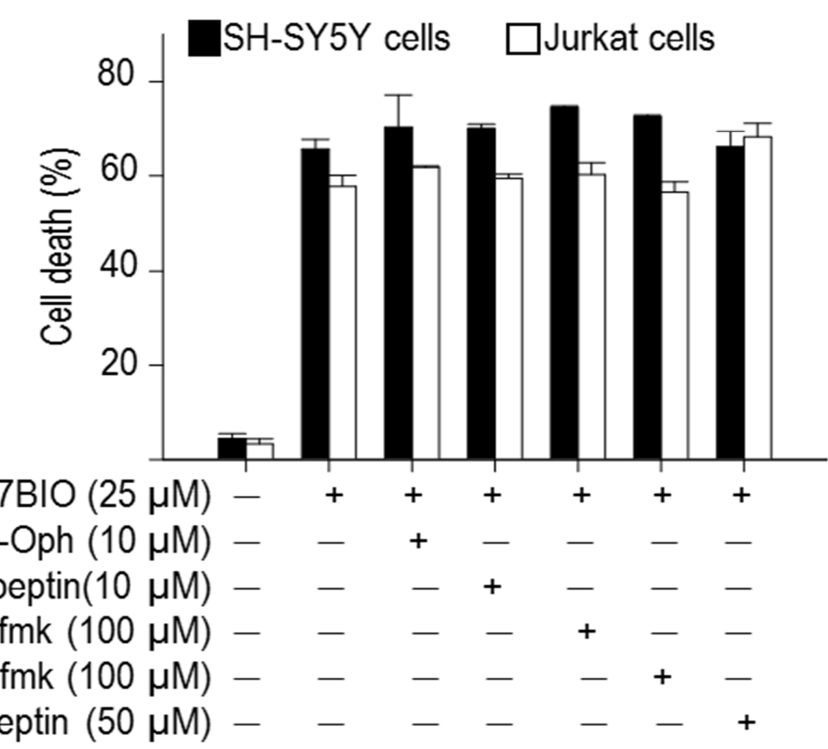

B

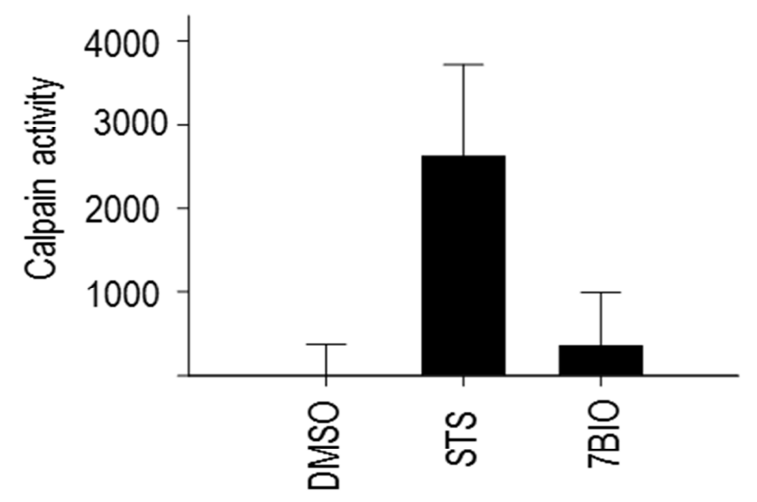

C

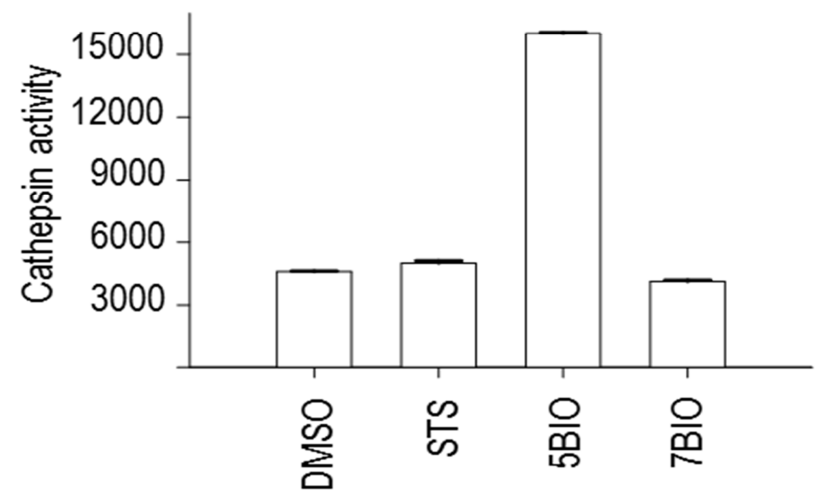


Fig. 10.

A

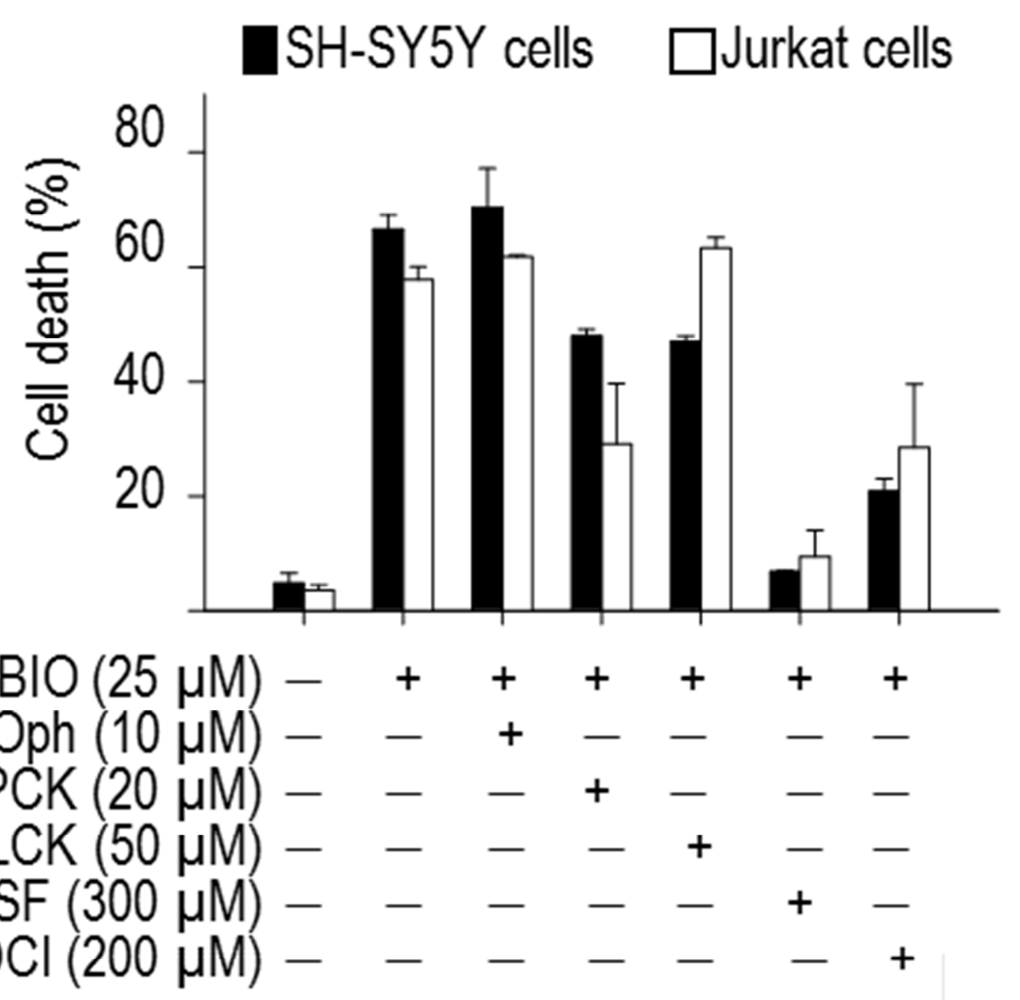

B

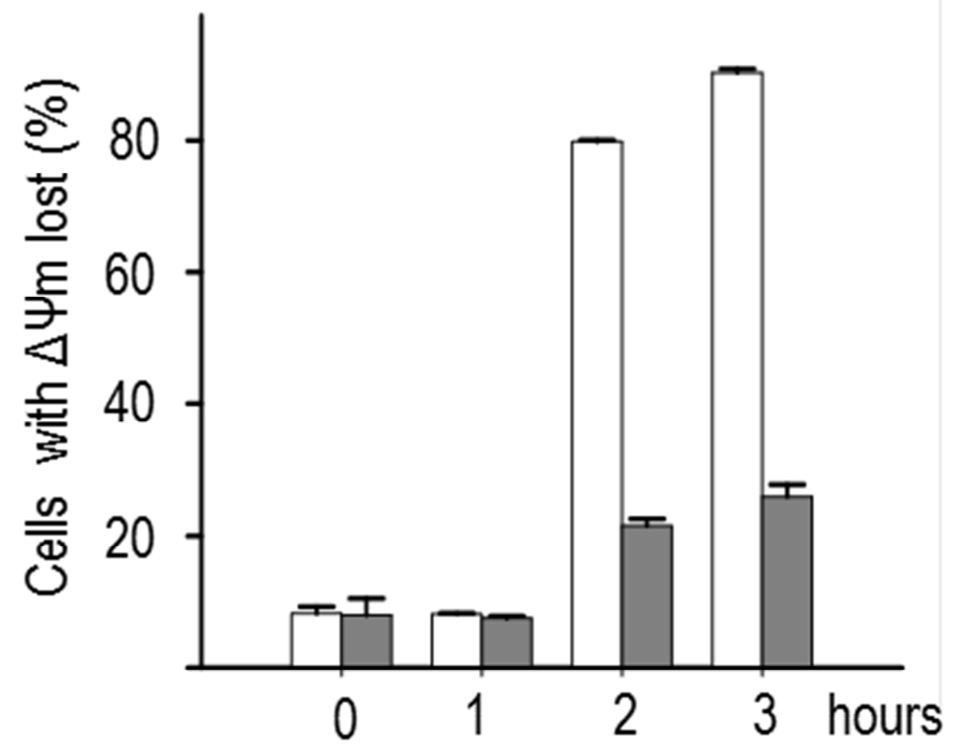

